\title{
CONEXIDADE POPULACIONAL DE Grapholita molesta (BUSCK, 1916) (LEPIDOPTERA: TORTRICIDAE) ENTRE POMARES DE PESSEGUEIRO E MACIEIRA
}

\section{CONNECTEDNESS OF Grapholita molesta (BUSCK, 1916) (LEPIDOPTERA: TORTRICIDAE) POPULATION BETWENN PEACH AND APPLE ORCHARDS}

\author{
Alex Sandro POLTRONIERI ${ }^{1}$ \\ Lino Bittencourt MONTEIRO² \\ Joselia Maria SCHUBER ${ }^{3}$ \\ Nério Aparecido CARDOSO 4
}

\begin{abstract}
RESUMO
A mariposa-oriental, Grapholita molesta é uma importante praga para as culturas do pessegueiro e macieira, podendo deslocar-se entre pomares em busca de hospedeiros. O objetivo deste trabalho foi verificar a conexidade populacional de $G$ molesta entre pomares de pessegueiro e macieira. Foram instaladas armadilhas com feromônio entre um pomar de pessegueiros 'Chimarrita' e um pomar de macieiras 'Eva' e entre um pomar de pessegueiros 'Texano' e um pomar de macieiras 'Eva'. Não se verificou conexidade entre as populações dos pomares 'Chimarrita' e 'Eva', enquanto que as populações dos pomares 'Texano' e 'Eva' comportaram-se como uma só.

Palavras-chave: Mariposa-oriental, Ecologia de populações, Prunus, Malus.
\end{abstract}

\begin{abstract}
The Oriental fruit moth is an important pest of peach and apple orchards, once it is able to move among the orchards in search of hosts. The aim of this work was to check the connectedness of $G$. molesta population between peach and apple orchards. Pheromone traps were installed in the orchard of peaches 'Chimarrita' and the orchard of apples 'Eva' and in the orchard of peaches 'Texano' and the orchard of apples 'Eva'. Connectedness was not verified among the populations of the orchards 'Chimarrita ' and 'Eva ', while the populations of the orchards 'Texano ' and 'Eva ' behaved as one.

Key-words: Oriental-fruit-moth, Population ecology, Prunus, Malus.
\end{abstract}

\footnotetext{
$1 \mathrm{Eng}^{\circ} \mathrm{agr}^{\circ}$, aluno de mestrado do Programa de Pós-Graduação em Agronomia, Dept. de Fitotecnia, CCA/UFPR, Curitiba, PR. Bolsista Capes. Rua Osmário de Lima, 578. Bairro Capão da Imbuia, Curitiba - PR, Email: alex.poltronieri@yahoo.com.br Autor para correspondência. 2 Eng $^{\circ}$ agr $^{\circ}$, Dr. Professor do Programa de Pós-Graduação em Agronomia, Dept. de Fitotecnia, CCA/UFPR, Curitiba, PR. Email: lbmonteiro@terra.com.br

3 Eng $^{\mathrm{a}}$ agr $^{\mathrm{a}}$, aluna de mestrado do Programa de Pós-Graduação em Agronomia, Dept. de Fitotecnia, CCA/UFPR, Curitiba, PR. Bolsista CNPq. Email: joseliaschuber@yahoo.com.br

4 Estatístico, aluno de mestrado do Programa de Pós-Graduação em Agronomia, Dept. de Fitotecnia, CCA/UFPR, Curitiba, PR. Email: neriocardoso@hotmail.com
} 


\section{INTRODUÇÃO}

A mariposa-oriental, Grapholita molesta (Busck, 1916) (Lepidoptera: Tortricidae), é uma importante praga para pessegueiros e macieiras (HUGHES e DORN, 2002; IL'CHEV et al., 2004; MYERS et al., 2006). Nas duas culturas os danos causados pelas lagartas são similares. Em ramos alimentam-se do meristema apical (GONZALEZ, 2003) e nos frutos abrem galerias na polpa (SALLES, 1991; NORA e HICKEL, 2002).

$O$ inseto tem hábitos migratórios e crepusculares, cujo vôo ocorre entre 17:00 e 22:00 horas (NORA e HICKEL, 2002). Em hipótese, o hábito migratório da mariposa poderia promover o seu deslocamento entre parcelas de um mesmo pomar, ou até mesmo entre pomares. Em pomares de pessegueiros o deslocamento de G. molesta ocorre com maior intensidade após a colheita das cultivares precoces, levando o inseto a buscar pomares formados por cultivares de ciclo médio e tardio (NUNES et al., 2003).

Segundo GONZALEZ (2003) a mariposaoriental desloca-se facilmente por 1 a $2 \mathrm{~km}$, podendo mover-se entre pomares. Entretanto estudos que venham a suprir a ausência de informações sobre o deslocamento das populações do inseto nos pomares após a colheita ainda são escassos no Brasil. Essa falta de informações sobre a conexidade entre populações de $G$. molesta de diferentes pomares preocupa produtores e técnicos, pois, incrementos populacionais da praga em pomares com ciclos médios e tardios de maturação de frutos podem elevar as perdas. Por precaução, são realizadas pulverizações preventivas de inseticidas nos pomares próximos àqueles onde já ocorreu a colheita (RIBEIRO, 2004), sendo esses tratamentos prejudiciais ao ambiente, à entomofauna dos pomares e eventualmente a saúde humana (BOTTON et al., 2001; AFONSO et al., 2002; ARIOLI et al., 2005).

Informações sobre a conexidade entre populações de G. molesta de diferentes pomares são importantes para a elaboração de estratégias no manejo da praga, visando reduzir as pulverizações de inseticidas, minimizar os riscos ao ambiente e a saúde humana. Assim o objetivo deste estudo foi o de verificar a conexidade populacional de G. molesta entre dois pomares de pessegueiros e um de macieiras.

\section{MATERIAL E MÉTODOS}

O estudo da conexidade populacional de $\mathrm{G}$. molesta entre pomares foi realizado entre julho de 2005 e janeiro de 2007, na Lapa, PR (Lat.: 2546' S., Lon.: $49^{\circ} 42^{\prime}$ W. e $908 \mathrm{~m}$ alt.).

\section{Áreas experimentais}

Área 1: formada por um pomar de pessegueiros 'Chimarrita' e um pomar de macieiras 'Eva', tendo entre eles $241 \mathrm{~m}$ de distância, onde está localizada uma área de cultivo de grãos de
156 m de distância, dividida por uma mata de Araucária, com 85 m de extensão (Figura 1). O pomar 'Chimarrita' foi implantado em 1999 em 0,9 ha, conduzido em taça com quatro ramos primários, no espaçamento $2 \times 5 \mathrm{~m}$. O pomar de macieiras 'Eva' foi implantado em 1998 em 1,3 ha, conduzido em líder central no espaçamento 1,5 x $3 \mathrm{~m}$.

Área 2: formada pelos pomares de pessegueiros 'Texano' e macieiras 'Eva', havendo uma área de campo de $60 \mathrm{~m}$ entre eles (Figura 1). $\mathrm{O}$ pomar 'Texano' foi implantado em 2003, em 0,5 ha, conduzido em taça com quatro ramos primários no espaçamento $3 \times 4 \mathrm{~m}$. O pomar de macieiras 'Eva' é o mesmo descrito na formação da primeira área.

\section{Fases de avaliação}

As avaliações ocorreram em três fases fenológicas do pessegueiro: desenvolvimento de frutos (fecundação do ovário a colheita), pós-colheita (entre o final da colheita e a dormência) e dormência (a partir de abril até o lançamento de novas brotações).

Na área 1, a fase de dormência em 2005/ 06 foi considerada de julho a agosto, e em 2006/07 de abril a julho. A diferença se deve ao fato de que o experimento foi iniciado na safra 2005/06 em julho e o início do lançamento das brotações do pessegueiro foi em setembro, e na safra 2006/07 houve uma antecipação das brotações, que ocorreram em agosto. O desenvolvimento de frutos, de pessegueiro, em 2005/06 ocorreu entre setembro e novembro, com o final da colheita em 23/11/05, e em 2006/07 entre agosto e novembro com o final da colheita em 15/11/06. A pós-colheita em ambas as safras iniciou em novembro, com as avaliações da safra 2005/06 sendo realizadas até março/2006, e em 2006/07 até janeiro/07, quando foi finalizada a colheita no pomar de macieiras.

$\mathrm{Na}$ área 2, o desenvolvimento de frutos da safra 2005/06 foi de setembro a outubro e em 2006/ 07 de agosto a outubro. A pós-colheita em ambas as safras iniciaram em novembro, sendo que em 2005/06 as avaliações foram até março/06 e em 2006/07 até janeiro/07. A dormência só foi avaliada na safra 2006/07, entre abril e julho.

\section{Flutuação populacional de G. molesta}

Para verificar a flutuação de $G$. molesta foram instaladas armadilhas Delta, com feromônio sexual marca Biografolita ${ }^{\circledR}$, na parte externa das plantas, a uma altura de $1,70 \mathrm{~m}$, no ramo primário voltado para o poente. O monitoramento das armadilhas foi realizado semanalmente a partir de julho/05 na área 1 ('Chimarrita' e 'Eva') e na área 2 ('Texano' e 'Eva') iniciou-se em setembro/05. As mariposas encontradas foram contadas e retiradas, o difusor de feromônio foi trocado a cada seis semanas e o piso adesivo substituído, quando necessário.

O nível de controle (NC), para G. molesta foi definido em vinte insetos/armadilha/semana (SALLES, 1991), durante as fases de desenvolvimento e maturação dos frutos. Os produtos fitossanitários utilizados para o controle de G. molesta foram o Dimethoate e Fenitrothion. 


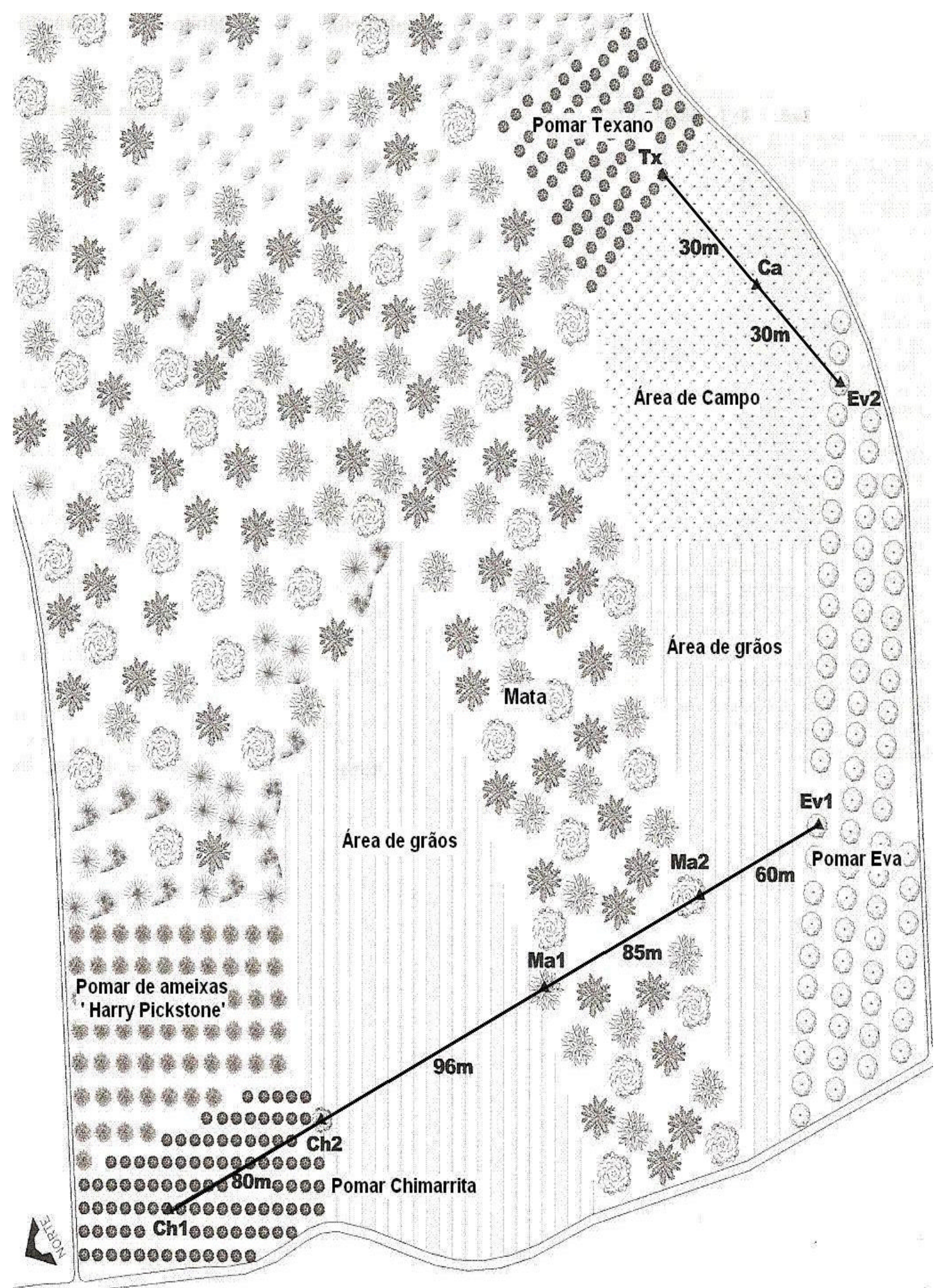

FIGURA 1 - Croqui do posicionamento das armadilhas delta entre os pomares de pessegueiros ' Chimarrita' e macieiras 'Eva', e entre os pomares de pessegueiros 'Texano' e macieiras 'Eva'. Lapa, PR - jul 2005/ jan 2007 
$\mathrm{Na}$ safra 2005/06 as pulverizações no pomar de pessegueiros 'Chimarrita' ocorreram em 25/09, 30/09, 15/10 e 27/10/05. No pomar 'Texano', ocorreram em 12/10, 21/10, 14/12/05 e 21/01/06 e no pomar de macieiras 'Eva' em 15/09, 03/10, 28/10 e 18/11/05. Na safra $2006 / 07$ as pulverizações no pomar de pessegueiros 'Chimarrita' ocorreram em 07/09, 03/10, 15/10 e 27/10/06 e 27/10/05. No pomar 'Texano', ocorreram em 07/09, 28/10, 12/12/06 e 18/01/07 e no pomar de macieiras 'Eva' em 18/10, 31/10, 16/11, e 25/11/06.

As capturas registradas nas diferentes fases fenológicas do pessegueiro foram comparadas pelo teste de Duncan $(p<0,05)$, além da realização de correlações entre as capturas de $G$. molesta feitas pelas armadilhas localizadas entre os pomares (Pearson, $p<0,001$ ).

Pontos de monitoramento entre os pomares de 'Chimarrita' e 'Eva'

Entre os pomares 'Chimarrita' e 'Eva', foram instaladas 5 armadilhas, em linha reta. A armadilha 1 foi instalada dentro do pomar 'Chimarrita' (Ch1), a armadilha 2 foi colocada na bordadura sul do pomar (Ch2), fazendo divisa com a área de cultivo de grãos, distante $80 \mathrm{~m}$ da Ch1. A armadilha 3 foi instalada na área de grãos, em uma árvore na bordadura da mata de Araucária (Ma1), distante $96 \mathrm{~m}$ da Ch2, e a armadilha 4 foi disposta do outro lado da mata (Ma2), a $85 \mathrm{~m}$ da Ma1. A armadilha 5 foi colocada na primeira linha da bordadura do pomar de macieiras 'Eva'(Ev1), distante $60 \mathrm{~m}$ da Ma2.

Pontos de monitoramento entre os pomares 'Texano' e 'Eva'

Entre os pomares 'Texano' e 'Eva' foram instaladas 3 armadilhas, a Delta 1 foi instalada na bordadura do 'Texano'(Tx). A Delta 2 (Ca) foi colocada em uma área de campo entre os pomares, distante 30 metros da Tx e a Delta 3 foi instalada na primeira linha da bordadura do pomar de 'Eva'(Ev2), distante $30 \mathrm{~m}$ da armadilha Ca e $60 \mathrm{~m}$ da Tx.

\section{RESULTADOS E DISCUSSÃO}

\section{Conexidade populacional de G. molesta entre os pomares 'Chimarrita e 'Eva'}

As avaliações revelaram que as maiores capturas do inseto ocorreram nas armadilhas Ch1 e Ch2, localizadas no pomar de pessegueiros 'Chimarrita', com a pós-colheita sendo caracterizada como o período onde houve o maior número de indivíduos capturados (Figura 2). As armadilhas localizadas nas bordas da mata (Ma1 e Ma2) apresentaram em todo o período de avaliação, as menores capturas de G. molesta, diferenciando-se significativamente das armadilhas localizadas nos pomares (Tabela 1).

No final da fase de dormência da safra $2005 / 06$, as capturas mais elevadas ocorreram no início de agosto, na armadilha Ch2, diferenciandose das capturas realizadas no pomar de macieiras, que não atingiram dez indivíduos/semana (Figura
2). Segundo ARIOLI et al.(2005), o pico populacional de G. molesta registrado em agosto no pomar de pessegueiros pode ter sua origem nos insetos que passaram o inverno em diapausa. Nas armadilhas Ma1 e Ma2 a média de capturas não ultrapassou dois indivíduos/semana, enquanto nos pomares estas chegaram a ser $80 \%$ superiores (Tabela 1 ).

A captura de G. molesta nas armadilhas Ch1, Ch2 e Ev1, durante a dormência do pessegueiro, em hipótese, sugere que os insetos adultos que vão originar as futuras populações passam o inverno nos pomares. POLTRONIERI et al. (2008) verificando a presença de $G$. molesta, em áreas de mata distantes 100 metros de pomares de pessegueiro, não obtiveram capturas, enquanto estas ocorriam nas armadilhas localizadas nas áreas de pessegueiros. A ausência de conhecimento sobre um hospedeiro alternativo nas matas adjacentes aos pomares (SALLES, 2000; POLTRONIERI et al., 2008) é outro fator que também condicionaria a permanência do inseto nos pomares.

$\mathrm{Na}$ fase de desenvolvimento de frutos da safra 2005/06 ocorreram baixas populações de adultos até próximo ao final da colheita (Figura 2). Observando as capturas médias verificou-se que foram semelhantes às ocorridas na dormência (Tabela 1), provavelmente devido às pulverizações de inseticidas que mantiveram baixas as populações do inseto nos pomares. As armadilhas Ma1 e Ma2 tiveram nesta fase um baixo número de capturas, fato que indica que os insetos que se desenvolveram no pessegueiro não tenham se deslocado para o pomar de macieiras, promovendo uma conexão entre as populações.

$\mathrm{Na}$ fase de pós-colheita verificaram-se altos níveis populacionais de adultos de $G$. molesta no pomar 'Chimarrita' (Figura 2), como foi observado por ARIOLI et al. (2005) em Bento Gonçalves, RS. $O$ incremento na população de G. molesta é justificado, pois nesta fase não ocorrem pulverizações com inseticidas no pomar, além da disponibilidade alimentar e elevadas temperaturas, que reduzem o período de desenvolvimento do inseto (GRELLMANN, et al., 1992). Na pós-colheita do pessegueiro, ocorreu a colheita no pomar de macieiras. Esta fase, caracterizada por elevadas populações de G. molesta, seria o melhor momento para a movimentação de indivíduos entre os dois pomares evidenciando a conexidade populacional. Entretanto, isto parece não ter ocorrido, pois o NC no pomar de macieiras não foi atingido nesta fase (Figura 2). Além da baixa ocorrência do inseto no pomar de macieiras, as capturas nas armadilhas Ma1 e Ma2 não ultrapassaram um individuo/semana, reforçando a tese da inexistência de conexão entre as populações destes pomares (Tabela 1).

$\mathrm{Na}$ fase de desenvolvimento de frutos da safra 2006/07, as capturas de G. molesta não atingiram o NC no pomar 'Chimarrita', sendo que no pomar de macieiras as capturas foram inferiores às registradas no pomar de pessegueiros (Figura 2). Embora no cômputo médio mensal está diferença não tenha sito tão 


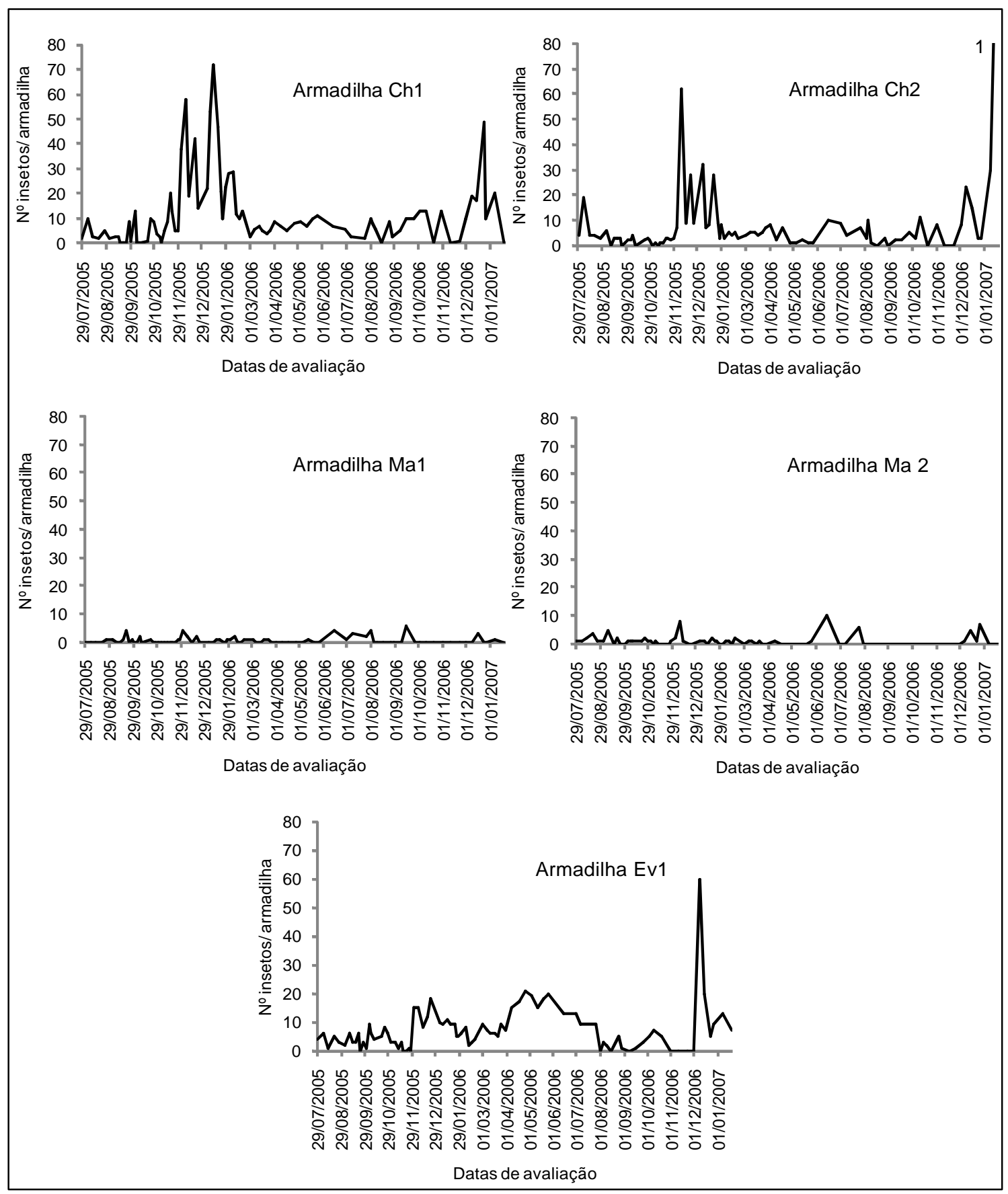

FIGURA 2 - Flutuação populacional de G. molesta com armadilhas de feromônio localizadas em pomares de pessegueiros 'Chimarrita' e macieiras 'Eva'. Lapa, PR - jul 2005 / jan 2007. Nota: Ch1 (instalada no pomar 'Chimarrita'), Ch2 (bordadura do pomar 'Chimarrita'), Ma1 (entre área de mata e área de cultura de grãos que delimita o pomar 'Chimarrita'), Ma2 (entre área de mata e a área de cultura de grãos que delimita o pomar 'Eva'), Ev1 (bordadura do pomar de macieiras 'Eva').

expressiva. As armadilhas Ma1 e Ma2 tiveram uma média de capturas inferior a um individuo/semana, diferenciando-se das demais armadilhas (Tabela 1). Nas duas safras, as capturas registradas pelas armadilhas Ma1 e Ma2 não apresentaram correlação com as capturas ocorridas nos pomares, sugerindo a inexistência de trânsito de insetos entre os pomares.

A fase pós-colheita no pessegueiro foi avaliada até 19/01/07, coincidindo com o final da colheita no pomar de macieiras. Nesta fase ocorreram elevados níveis populacionais nos pomares, sendo registrados os maiores níveis de captura na armadilha Ch2 (Figura 2). Nas armadilhas Ma1 e Ma2 as capturas não ultrapassaram dois indivíduos / semana, diferenciando-se significativamente das armadilhas localizadas nos pomares (Tabela 1). 
Durante as fases de avaliação, as armadilhas Ma1 e Ma2 apresentaram baixos índices de capturas de G. molesta, sendo que este fato pode estar relacionado à distância entre os pomares, pois a capacidade de dispersão diminui com o aumento da distância entre a população e a área a ser colonizada (VITAL et al., 2004).

TABELA 1 - Número médio de capturas mensais de machos adultos de G. molesta em cinco armadilhas Delta: Ch1, instalada no pomar de pessegueiros 'Chimarrita'; Ch2, bordadura do pomar; Ma1, entre a mata e a área de cultivo de grãos que delimita o pomar de 'Chimarrita'; Ma2, entre a mata e a área de cultura de grãos que delimita o pomar de macieiras 'Eva'; Ev1, bordadura do pomar de macieiras. Fases de desenvolvimento de frutos, pós-colheita e dormência baseada sobre o pessegueiro 'Chimarrita'. Lapa, PR. - jul 2005/jan 2007

\begin{tabular}{|c|c|c|c|c|c|c|}
\hline \multirow{2}{*}{ Safra } & \multirow{2}{*}{ Fases fenológicas do pessegueiro } & \multicolumn{5}{|c|}{$\mathrm{N}^{\circ}$ de indivíduos nas armadilhas Delta } \\
\hline & & Ch1 & Ch2 & Ma1 & Ma2 & Ev1 \\
\hline \multirow{3}{*}{$2005 / 06$} & Dormência & $4,0 \mathrm{~b}$ & $6,7 \mathrm{bc}$ & $0,3 \mathrm{a}$ & $1,7 \mathrm{a}$ & $3,5 b$ \\
\hline & Desenvolvimento de frutos & $5,1 \mathrm{bc}$ & $1,7 \mathrm{~b}$ & $0,5 \mathrm{a}$ & $0,8 \mathrm{a}$ & $3,6 \mathrm{~b}$ \\
\hline & Pós-Colheita & $22,2 \mathrm{c}$ & $10,8 b$ & $0,8 \mathrm{a}$ & $1,0 \mathrm{a}$ & $7,9 \mathrm{~b}$ \\
\hline \multirow{3}{*}{$2006 / 07$} & Dormência & $6,8 \mathrm{~b}$ & $4,0 \mathrm{~b}$ & $1,0 \mathrm{a}$ & $1,6 \mathrm{a}$ & $15,3 \mathrm{c}$ \\
\hline & Desenvolvimento de frutos & $7,2 \mathrm{c}$ & $3,4 \mathrm{~b}$ & $0,7 \mathrm{a}$ & $0,0 \mathrm{a}$ & $2,3 b$ \\
\hline & Pós-Colheita & $17,9 \mathrm{~b}$ & $37,4 \mathrm{c}$ & $0,6 \mathrm{a}$ & $2,0 \mathrm{a}$ & $16,3 \mathrm{~b}$ \\
\hline
\end{tabular}

\begin{tabular}{|c|c|c|c|c|c|c|}
\hline \multirow{2}{*}{ Safra } & \multirow{2}{*}{ Fases fenológicas do pessegueiro } & \multicolumn{5}{|c|}{$\mathrm{N}^{\circ}$ de indivíduos nas armadilhas Delta } \\
\hline & & Ch1 & Ch2 & Ma1 & Ma2 & Ev1 \\
\hline \multirow{3}{*}{$2005 / 06$} & Dormência & $4,0 \mathrm{~b}$ & $6,7 \mathrm{bc}$ & $0,3 \mathrm{a}$ & $1,7 \mathrm{a}$ & $3,5 b$ \\
\hline & Desenvolvimento de frutos & $5,1 \mathrm{bc}$ & $1,7 \mathrm{~b}$ & $0,5 \mathrm{a}$ & $0,8 \mathrm{a}$ & $3,6 \mathrm{~b}$ \\
\hline & Pós-Colheita & $22,2 \mathrm{c}$ & $10,8 b$ & $0,8 \mathrm{a}$ & $1,0 \mathrm{a}$ & $7,9 \mathrm{~b}$ \\
\hline \multirow{3}{*}{$2006 / 07$} & Dormência & $6,8 \mathrm{~b}$ & $4,0 \mathrm{~b}$ & $1,0 \mathrm{a}$ & $1,6 \mathrm{a}$ & $15,3 \mathrm{c}$ \\
\hline & Desenvolvimento de frutos & $7,2 \mathrm{c}$ & $3,4 \mathrm{~b}$ & $0,7 \mathrm{a}$ & $0,0 \mathrm{a}$ & $2,3 b$ \\
\hline & Pós-Colheita & $17,9 \mathrm{~b}$ & $37,4 \mathrm{c}$ & $0,6 \mathrm{a}$ & $2,0 \mathrm{a}$ & $16,3 b$ \\
\hline
\end{tabular}

Nota: Médias seguidas por letras distintas, na linha, diferem estatisticamente entre si pelo teste de Duncan ( $p<0,01)$.

Estas informações confirmam a inexistência de conexidade entre as populações de G. molesta dos pomares de pessegueiros 'Chimarrita' e macieiras 'Eva', pois apesar de estarem em um mesmo agroecossitema, há a presença de duas barreiras promovidas pelos 241 $\mathrm{m}$ entre os pomares e por um obstáculo natural constituído pela mata de Araucária. Corroboram com essas informações o trabalho de ROTHSCHILD e VICKERS (1991), que estudando o movimento de $G$. molesta, veficaram que a maioria dos machos adultos não dispersa a distâncias superiores a 200 metros. Entretanto HUGHES e DORN (2002) alertam que estudos de dispersão, baseados no vôo de machos de G. molesta, podem subestimar as movimentações de indivíduos, pois as fêmeas são o principal agente migratório, apresentando uma maior capacidade de vôo.

SCIARRETTA e TREMATERRA (2006), estudando a distribuição espacial de G. molesta em uma região da Itália produtora de maçã, kiwi, pêssego, pêra e ameixa, concluíram que um rio que dividia os pomares atuou como uma barreira natural ao deslocamento do inseto entre as áreas. MALTA et al. (2005) estudando a flutuação de pragas em tomateiro, verificaram que uma barreira formada por capim colonião (Panicum maximum) com 3,2 m de altura, que separava as parcelas experimentais, foi eficiente para evitar a migração de insetos.

Conexidade populacional de G. molesta entre os pomares 'Texano' e 'Eva'

Entre os pomares 'Texano' e 'Eva' as flutuações de $G$. molesta foram maiores na fase de pós-colheita em ambas as safras (Figura 3). A 
distância entre os pomares parece não ter impedido o livre deslocamento do inseto, pois na maioria das capturas realizadas pelas armadilhas não houve diferença estatística (Tabela 2).

$\mathrm{Na}$ fase de desenvolvimento de frutos da safra 2005/06, a partir do final de setembro as capturas já extrapolavam o NC, sendo necessárias pulverizações em ambos os pomares. As pulverizações realizadas no pomar de pessegueiros 'Texano' foram feitas visando o controle de G. molesta, a fim de preservar a arquitetura da planta, pois era um pomar jovem, onde ainda estavam sendo formados os ramos primários que sustentariam os ramos de produção. As coletas de G. molesta registradas pelas armadilhas na fase de desenvolvimento de frutos mostraram semelhanças (Figura 3 ), pois as capturas registradas nas armadilhas Tx e Ca apresentaram uma forte correlação $(r=0,88 ; p<0,001)$. Essas informações evidenciam a conexidade entre as populações de G. molesta existentes nos pomares durante esta fase, sendo provável que o pomar de macieiras tenha sido a maior fonte de insetos, pois apresentou as maiores oscilações populacionais (Figura 3 ).

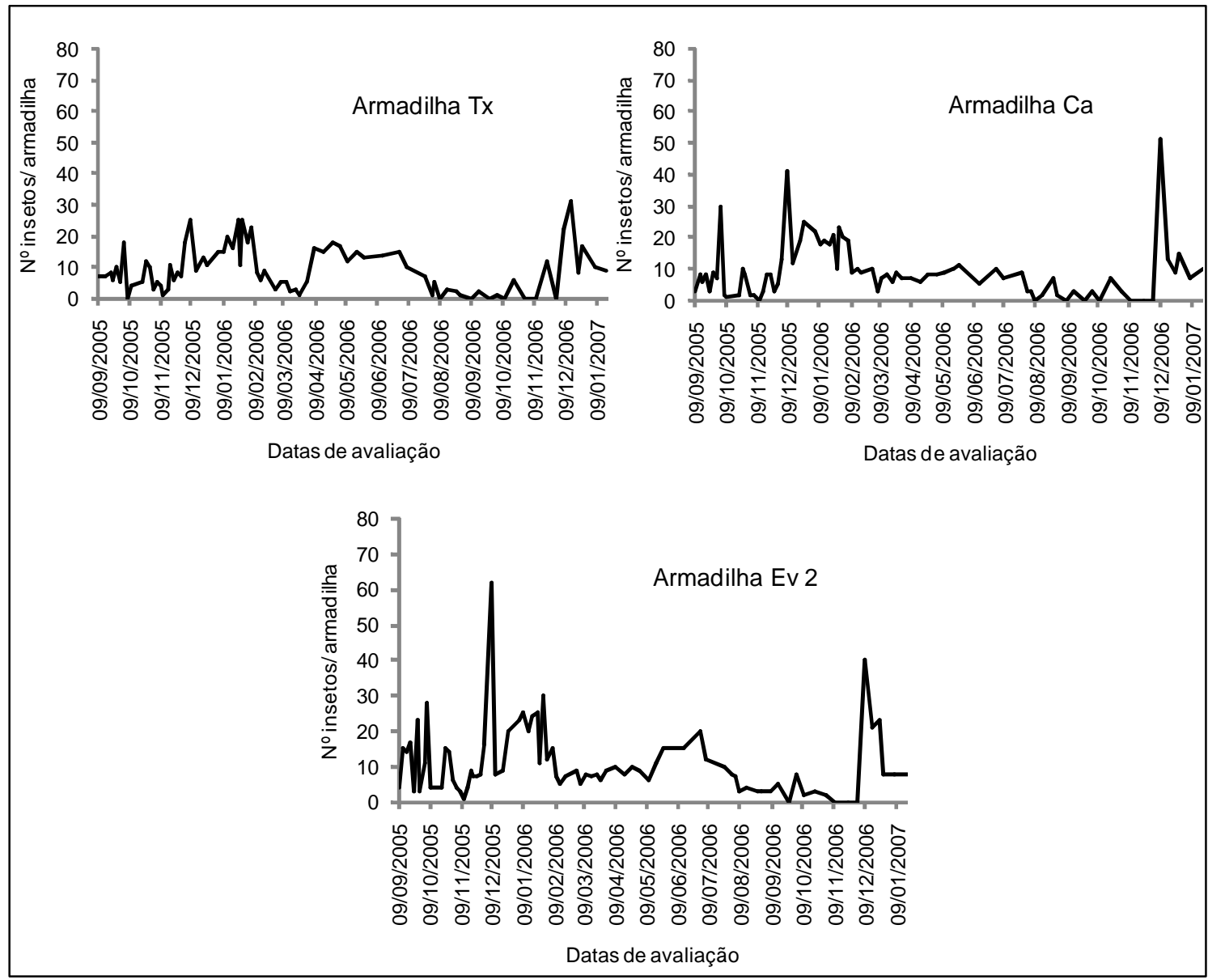

FIGURA 3 - Flutuação populacional de G. molesta com armadilhas de feromônio localizadas em pomares de pessegueiros 'Texano' e macieiras 'Eva'. Lapa, PR - jul. 2005/janeiro 2007. Nota: Tx (armadilha localizada no pomar de pessegueiros 'Texano'), Ca (armadilha localizada entre os pomares de pessegueiro e macieira), Ev2 (armadilha localizada no pomar de macieiras 'Eva'.

A fase de pós-colheita da safra 2005/06 foi onde ocorreram as maiores populações de $G$. molesta no pomar 'Texano'. Entretanto as pulverizações realizadas a fim de proteger a arquitetura da planta contribuíram para manter a população do inseto abaixo no NC (Figura 3). No pomar de macieiras não se realizaram tratamentos, por estar sendo feita a colheita, entretanto as capturas entre as armadilhas Tx, Ca e Ev2 não se diferenciaram estatisticamente (Tabela 2).

A ausência de pulverizações no pomar de macieiras poderia ter promovido um incremento populacional maior, entretanto a pequena distância e a ausência de barreiras físicas facilitaram o intercâmbio de indivíduos entre as populações existentes nos pomares. IL'CHEV (2002) relata que, em pomares australianos onde é usada a confusão sexual para o controle de G. molesta, as plantas que compõem a bordadura apresentavam maiores percentuais de danos em frutos, sento atribuído esse fato à migração de fêmeas acasaladas oriundas de áreas próximas. 
POLTRONIERI, A. S. et al. Conexidade populacional...

TABELA 2 - Número médio de capturas mensais de G. molesta registradas em três armadilhas delta instaladas entre pomar de pessegueiros 'Texano' e macieiras 'Eva'. Tx, instalada no pomar de pessegueiros; Ca, instalada em uma parcela de campo entre os pomares; Ev2, colocada no pomar de macieiras 'Eva'. Fases de desenvolvimento de frutos, pós-colheita e dormência baseada sobre o pessegueiro 'Chimarrita'. Lapa, PR. - jul 2005/jan 2007

\begin{tabular}{ccccc}
\hline \multirow{2}{*}{ Safra } & Fases fenológicas do pessegueiro & \multicolumn{2}{c}{$\mathrm{N}^{\circ}$ de indivíduos nas armadilhas Delta } \\
\cline { 3 - 4 } $2005 / 06$ & Desenvolvimento de frutos & $7,62 \mathrm{a}$ & $\mathrm{Ca}$ & Ev2 \\
\hline \multirow{2}{*}{$2006 / 07$} & Pós-Colheita & $10,27 \mathrm{a}$ & $11,92 \mathrm{~b}$ & $12,73 \mathrm{a}$ \\
\hline \multirow{2}{*}{ Dormência } & Desenvolvimento de frutos & $13,82 \mathrm{a}$ & $8,18 \mathrm{a}$ & $11,45 \mathrm{a}$ \\
& Pós-Colheita & $1,62 \mathrm{a}$ & $2,54 \mathrm{a}$ & $3,92 \mathrm{a}$ \\
\end{tabular}

Nota: Médias seguidas por letras distintas, na linha, diferem estatisticamente entre si pelo teste de Duncan $(p<0,01)$.

$\mathrm{Na}$ fase de pós-colheita da safra 2005/06 ocorreram correlações significativas entre as capturas de $G$. molesta realizadas pelas armadilhas Tx e Ca $(r=0,83 ; p<0,001)$, Tx e Ev2 $(r=0,77 ; p<0,001)$ e entre as armadilhas Ca e Ev2 $(r=0,90 ; p<0,001)$. $A$ análise da correlação reforça a tese de uma conexidade populacional de $G$. molesta, comportando-se a população do inseto como única entre os pomares.

A dormência da safra 2006/07 foi uma fase caracterizada pela ausência de tratamentos químicos nos pomares. Assim como ocorreu entre os pomares 'Chimarrita' e 'Eva', as flutuações populacionais registradas nesta fase nos pomares 'Texano' e 'Eva', revelaram médias de capturas superiores a onze indivíduos/semana, reforçando a hipótese de HICKEL et al. (2003) da ocorrência de diapausa não sincronizada para o inseto.

A fase de desenvolvimento de frutos da safra 2006/07 apresentou baixa ocorrência do inseto, com as capturas não atingindo dez indivíduos/semana (Figura 3 ), resultado das pulverizações de inseticidas sobre as populações de G. molesta.

A pós-colheita da safra 2006/07, foi novamente, a fase onde ocorreram as maiores flutuações do inseto (Figura 3). A média de capturas nesta fase teve uma variação inferior a $4 \%$, e assim como na pós-colheita da safra anterior, não ocorreram diferenças estatísticas (Tabela 2), havendo uma correção positiva entre as armadilhas Tx e Ev2 $(r=0,64 ; p<0,001)$. Esse comportamento apresentado pelo inseto nas duas safras agrícolas avaliadas denota a existência de trânsito de $G$. molesta entre os pomares, formando numa única população na área 2. Neste caso, a distância de apenas $60 \mathrm{~m}$, não foi um fator limitante para o deslocamento do inseto (VITAL et al., 2004). Além da curta distância, não havia barreira física separando os pomares como ocorreu entre os pomares de 'Chimarrita' e 'Eva'. Os dados obtidos estão em concordância com NUNES et al. (2003), que relatam o trânsito de $G$. molesta entre pomares devido à proximidade entre eles.

\section{CONCLUSÕES}

$\mathrm{Na}$ ausência de barreiras físicas e pequenas distâncias há conexidade populacional de G. molesta entre pomares de pessegueiro e macieira.

\section{REFERÊNCIAS}

1. AFONSO, A. P. S.; GRÜTZMACHER, A. D.; LOECK, A. E.; FACHINELLO, J. C.; HERPICH, M. I.; BECKMANN, M. Z. Flutuação populacional e danos de Grapholita molesta (Busck, 1916) (Lepidoptera: Tortricidae) em sistemas de produção convencional e integrada da cultura do pessegueiro na localidade de Pelotas, RS. Revista Brasileira de Agrociência, v. 8, n. 3, p. 225-229, 2002.

2. ARIOLI, J. C.; CARVALHO, G. A.; BOTTON, M. Flutuação populacional de Grapholita molesta (Busck) com armadilhas de feromônio sexual na cultura do pessegueiro em Bento Gonçalves, RS, Brasil. Ciência Rural, v. 32, n. 1, p. 1-5, 2005.

3. BOTTON, M.; ARIOLLI, C. J.; COLLETTA, V. D. Monitoramento da mariposa-oriental Grapholita molesta (Busck, 1916) na cultura do pessegueiro. Bento Gonçalves: Embrapa Uva e Vinho, 2001. 4 p. (Comunicado técnico, 30) 
4. GONZALEZ, H. R. Las polillas de la fruta en Chile (Lepidoptera: Tortricidae; Pyralidade). Santiago: Universidade de Chile, 2003. 188 p. (Série Ciências agronômicas, n. 9)

5. GRELLMANN, E. O.; LOECK A. E.; SALLES, L. A. B., FACHINELLO, J. C. Necessidades térmicas e estimativa do número de gerações de Grapholita molesta (Busck, 1916) (Lepidoptera: Olethreutidae) em pelotas, RS. Pesquisa Agropecuária Brasileira, v. 27, n. 7. p. 999-1004, 1992.

6. HICKEL, E. R.; VILELA, E. F.; DESOUZA, O. F. F.; MIRAMONTES, O. Previsão de atividade de vôo de Grapholita molesta (Busk) em pomares de pessegueiro e ameixeira, através do ajuste entre captura de adultos em armadilhas de feromônio e acumulação de calor. Revista de Ciências Agroveterinárias, v. 2, n. 1, p. 30-41, 2003.

7. HUGHES, J.; DORN, S. Sexual differences in the flight performance of the oriental fruit moth, Cydia molesta. Entomologia Experimentalis et Applicata, n. 103, p. 171-182, 2002.

8. IL'ICHEV, A. L. Area-wide mating disruption for improved control of Oriental Fruit Moth Grapholita molesta in Victoria, Australia. International Organization for Biological Control, v. 25, p. 1-13, 2002.

9. IL'ICHEV, A. L.; MILNER, W.; MILNER, A. D. Mating disruption barriers in pome fruit for improved control of oriental fruit moth Grapholita molesta (Lepidoptera: Tortricidae) in stone fruit under mating disruption. Journal Applied Entomology, v. 128, n. 2 p. 126-132, 2004

10. MALTA, A. W. O. ; RODRIGUES, E. J. R.; GONÇALVES, N. P.; REIS, P. R.; SILVA, R. A.; DELGIUDICE, M. P.; CALIL, A. C. P. Calibração dos níveis de ação para o controle populacional dos insetos vetores de viroses do tomateiro na meso-região metropolitana de Belo horizonte-MG. In: CONGRESSO BRASILEIRO DE OLERICULTURA, 45., 2005, Fortaleza. Anais... Fortaleza: Associação Brasileira de Horticultura, 2005. 4 p. 1 CD-ROM.

11. MYERS, C. T.; HULL, L. A.; KRAWCZYK, G. Comparative survival of oriental fruit moth (Lepidoptera: Tortricidae) larvae on shoots and fruit of apple an peach. Journal of Economic Entomology, v. 99, n. 4, p. 1299-1309, 2006.

12. NORA, I.; HICKEL, E. R. Pragas da macieira. In: EPAGRI - EMPRESA DE PESQUISA AGROPECUÁRIA E EXTENSÃO RURAL DE SANTA CATARINA. S. A. A cultura da macieira. Florianópolis: EPAGRI, 2002. p. $463-525$.

13. NUNES, J. L. S.; FARIAS, R. M.; GUERRA, D. S.; GRASSELLI, V.; MARODIN, G. A. B. Flutuação populacional e controle da mariposa-oriental (Grapholita molesta Busck, 1916) em produção convencional e integrada de pessegueiro. Revista Brasileira de Fruticultura, v. 25, n. 2, p. 227-228, 2003.

14. POLTRONIERI, A. S.; MONTEIRO, L. B.; SCHUBER, J. M. Prospecção da diapausa da mariposa-oriental no período de dormência do pessegueiro. Revista Scientia Agraria, v. 9, n. 1, p. 67-72, 2008.

15. RIBEIRO, L. G. Avanços no manejo da Grapholita molesta na cultura do pessegueiro. In: VII ENCONTRO NACIONAL SOBRE FRUTICULTURA DE CLIMA TEMPERADO, Fraiburgo, 2004. Anais... (local de publicação): EPAGRI, 2004. p. ??-??

16. ROTHSCHILD, G. H. L.; VICKERS, R. A. Biology, ecology and control of the Oriental Fruit moth. In: VAN DER GEEST, L. P. S.; EVENHUIS, H. H. World Crop Pests. Tortricid pests: their biology, natural enemies and control, v. 5, p. 389-412, 1991.

17. SALLES, L. A. B. Grafolita (Grapholita molesta): bioecologia e controle. Pelotas: EMBRAPA - CNPFT, 1991. 13 p. (EMBRAPA - CNPFT. Documentos, 42).

18. SALLES, L. A. Mariposa-oriental, Grapholita molesta (Lepidoptera: Tortricidae) In: VILELA, E. F.; ZUCCHI, R. A.; CANTOR, F. Histórico e impacto das pragas introduzidas no Brasil. Ribeirão Preto: Editora Holos, 2000. 173 p.

19. SCHIARRETTA, A.; TREMATERRA, P. Geostatistical characterization of the spatial distribution of Grapholita molesta and Anarsia lineatella males in agricultural Landscape. Journal of Applied. Entomology, v. 137, n. 2, p. 73-83, 2006.

20. VITAL, M. V. C.; VIEIRA. L. C. G.; CARVALHO, R. A.; COSTA, D. A. SILVA, L. C. F.; SILVEIRA, A. V. T.; FILHO, G. F. L. Insetos em experimentos de ecologia de populações: um exemplo de abordagem didática. Acta Scientiarum Biological Sciences, v. 26, n. 3, p. 287-290, 2004.

Recebido em 23/01/2008 Aceito em 11/06/2008 

